\title{
A ESPIRITUALIDADE NO CONTEXTO DA CIÊNCIA DA SAÚDE
}

\section{ARTIGO ORIGINAL}

GERONE, Lucas Guilherme Teztlaff de ${ }^{1}$

GERONE, Lucas Guilherme Teztlaff de. A espiritualidade no contexto da ciência da Saúde. Revista Científica Multidisciplinar Núcleo do Conhecimento. Ano 05, Ed. 09, Vol. 01, pp. 121-136. Setembro de 2020. ISSN: 2448-0959, Link de acesso: https://www.nucleodoconhecimento.com.br/ciencia-da-religiao/ciencia-dasaude

\section{RESUMO}

Contexto: A investigação acadêmica sobre espiritualidade e saúde tem sido temas das pesquisas nas áreas da saúde e da religião. Contudo, pouco se trata da espiritualidade em uma perspectiva da relação entre a religião com os profissionais da saúde. Objetivos: O presente estudo apresenta uma reflexão sobre a espiritualidade e saúde. Especificamente, busca evidenciar: a) a relação entre a religião e ciência da saúde; b) a relação entre a religião cristã e a saúde; c) e a tradição cristã e os profissionais da saúde. Método: Uma referência teórica sobre a espiritualidade no contexto de saúde. Resultados: a) existem associações etimológicas entre a espiritualidade e a saúde; b) a ciência religiosa sempre se atentou para a temática da saúde; c) A ideologia da religião cristã sobre a saúde estende-se no decorrer da história; d) encontra-se a influência da tradição cristã na prática do cuidado entre os profissionais da saúde. Considerações: a) Considera-se que a religião está associada

1 Mestre em Teologia pela PUC/PR. Possui Especialização em Comportamento Organizacional; Especialização em Neuropsicopedagogia; Especialização em Filosofia e Sociologia; Especialização em Docência do Ensino Superior. MBAs em Administração e Gestão com ênfase na espiritualidade e religiosidade nas empresas. Graduado em Gestão comercial. Bacharelado em Teologia. Possui Licenciatura em Filosofia e Licenciatura em Pedagogia. 
e historicamente com a saúde, b) considera-se que existe uma relação entre espiritualidade e saúde no sentido etimológico e na prática do cuidado em saúde; c) considera-se que a tradição religião cristã influenciou o contexto em saúde, tais como, a prática do cuidado entre os profissionais. Considere-se a importância de novas pesquisas sobre a espiritualidade e a saúde em outras óticas religiosas, tais como, o espiritismo.

Palavras-Chave: Espiritualidade, religião, saúde, cuidado, profissionais da saúde.

\section{INTRODUÇÃO}

A associação entre a espiritualidade e a saúde é histórica, durante o desenvolvimento humano e científico existe uma relação de proximidade entre a religião e a saúde, tais como, a prática de cuidado entre os profissionais da saúde. De fato, a medicina e a religião são áreas que têm em comum a questão do cuidado humano, expresso na atenção à saúde. Muitas civilizações antigas desenvolveram seu serviço de saúde na figura de um sacerdote médico, como, por exemplo, o poder divino de cura nas figuras dos xamãs, dos pajés das tribos indígenas, dos druidas das antigas civilizações europeias e dos curandeiros e feiticeiros das tribos africanas e da Oceania.

$\mathrm{Na}$ Idade Média (uma época expoente da influência da Igreja Católica) era comum o médico desempenhar o cuidado hospitalar e o religioso, como a de orações no tratamento dos enfermos. Devido ao avanço científico na Idade Moderna, houve um período de afastamento entre as questões religiosas e a saúde (HEIMANN, 2003). Atualmente, a influência da religiosidade/espiritualidade no estado de saúde-doença desperta o interesse entre clínicos e pesquisadores na área de saúde (MOREIRAALMEIDA, 2010). Por exemplo, A medicina contemporânea foca-se, no cuidado com a saúde física, mas, também, em questões que são pertinentes a religião, como olhar a saúde em uma perspectiva da relacionalidade (cuidado na relação com outros, consigo próprio e com a transcendência).

Existem grupos religiosos que se propõem a buscar a saúde como uma de suas finalidades religiosas. São religiões que prescrevem e proscrevem doutrinas ou 
ensinamentos sobre um comportamento saudável (LEVIN, 2003). Em um estudo, Levin (2003) aponta 32 grupos religiosos e tradições de fé no mundo que possuem crenças específicas aos eventos relativos à saúde, como por exemplo: ao sangue e aos produtos do sangue, à eutanásia, à cura, a práticas de cura, a medicamentos, à doação de órgãos, a questões sobre o direito de morrer, a procedimentos cirúrgicos e ao recebimento de visitas. Especificamente neste estudo, percebe-se que a religião cristã possuir uma atuação na ciência da saúde. Encontra-se na tradição cristã uma associação entre o "corporal e espiritual". Atualmente, a associação entre o corpo e o espírito faz parte dos discursos sobre um cuidado em saúde humanizado, pois, o uso indiscriminado da tecnologia, ainda que proporcione a cura corporal, pode resultar no abandono, muitas vezes não intencional, de outras dimensões humanas respeitáveis, como o conforto e o controle da dor, a comunicação, os valores significativos e, especialmente, as questões espirituais e religiosas. Neste sentido, surge "um desafio aos profissionais da saúde para responder às questões sobre o equilíbrio entre saúde e espiritualidade" (PERES, 2007, p. 86).

\section{DESENVOLVIMENTO}

\section{DEFINIÇÕES DAS TERMINOLOGIAS: RELIGIOSIDADE, ESPIRITUALIDADE E SAÚDE}

No meio acadêmico, existe uma associação comum entre religiosidade e espiritualidade. Para o médico norte-americano Harold G. Koenig (2012, p. 12), autoridade mundial no conhecimento de religiosidade e saúde, a maior parte dos estudos sobre estes temas utiliza "o termo espiritualidade no título ou na discussão dos resultados". Por isso, neste estudo, religiosidade e espiritualidade aparecem unidas, separadas apenas por uma barra (/). Todavia, mesmo existindo esta associação, não se pode considerar religiosidade e espiritualidade como sinônimos.

De um lado, a religiosidade é uma qualidade daquilo que faz parte da religião, aqui entendida a partir de sua etimologia latina, religare, que significa "religação" entre o homem e Deus (DERRIDA, 2000). De acordo com Koenig (2012, p.11), religião é um 
sistema de crenças e práticas observado por um grupo de pessoas que se apoiam em rituais ou em um conjunto de escrituras e ensinamentos "que reconhecem, idolatram, comunicam-se com ou se aproximam do Sagrado, do Divino, de Deus".

Por outro lado, a espiritualidade é uma qualidade da natureza do espírito, um fator pertinente a todo ser humano. A espiritualidade se constitui num domínio fora do sistema religioso, e pode estar presente em qualquer experiência humana - como, por exemplo, em seus valores, ética, moral, no amor, na compaixão, na arte, ligado à conexão, paz interior, energia, esperança, alegria, força, suporte, amizade, solidariedade, humanismo, conforto - e, notoriamente, no sentido e no propósito da vida (GERONE, 2015).

Para Puchalski (2006, pp. 14-15), médica e uma das pioneiras no movimento para integrar a espiritualidade nos cuidados de saúde, espiritualidade é a:

busca inerente de cada pessoa do significado e do propósito definitivo da vida. Esse significado pode ser encontrado na religião, mas, muitas vezes pode ser mais amplo do que isso, incluindo a relação com uma figura divina ou com a transcendência, relações com os outros, bem como a espiritualidade encontrada na natureza, na arte e no pensamento racional. Todos esses fatores podem influenciar o modo como os pacientes e os profissionais da saúde percebem a saúde e a doença e como interagem uns com os outros.

Os fatores que permeiam a noção de espiritualidade, como sentido e propósito de vida, paz interior, compaixão, suporte social, esperança, dentre outros, influenciam as percepções sobre a noção de saúde dos pacientes e dos profissionais da saúde, porque estes fatores de espiritualidade se tornam um indicador positivo para a saúde. Neste contexto, espiritualidade é um dos indicadores da noção de saúde.

Para o Grupo de Avaliação da Qualidade de Vida da Divisão de Saúde Mental da Organização Mundial de Saúde (WHOQOL GROUP; OMS, 1994), a saúde está relacionada à qualidade de vida, o que pode ser a intuição do ser humano sobre a sua condição de vida, de acordo com o contexto cultural. Ainda, é a estrutura de princípios com os quais o ser humano relaciona seus objetivos, expectativas, padrões e preocupações. Portanto, a qualidade de vida diz respeito a diversas noções de saúde: 
(a) biológicas e funcionais, como status de saúde, status funcional e incapacidade; e

(b) sociais e psicológicas, como bem-estar, satisfação, felicidade e origem econômica (PANZINI et al, 2007). Por isso, Luz (2009) afirma que se acrescentou a dimensão espiritual à noção de saúde, visto que a religiosidade/espiritualidade influencia toda a vida - os valores, os comportamentos, a política, a economia, a cultura, a educação —, os quais se refletem diretamente na noção de saúde.

\section{AS RELIGIÕES E A CIÊNCIA DA SAÚDE}

Existem grupos religiosos que se propõem a buscar a saúde como uma de suas finalidades religiosas. São religiões que prescrevem e proscrevem doutrinas ou ensinamentos sobre um comportamento saudável (LEVIN, 2003). Em um estudo, Levin (2003) aponta 32 grupos religiosos e tradições de fé no mundo que possuem crenças específicas aos eventos relativos à saúde, como por exemplo: ao sangue e aos produtos do sangue, à eutanásia, à cura, a práticas de cura, a medicamentos, à doação de órgãos, a questões sobre o direito de morrer, a procedimentos cirúrgicos e ao recebimento de visitas.

O processo de as religiões prescreverem e proscreverem o que é saudável ou não impacta significativamente a saúde dos seus fiéis. Por um lado, existem algumas religiões com condutas fundamentalistas em relação à saúde dos seus fiéis, as quais fogem da visão médica tradicional, como, por exemplo, a proibição de determinados medicamentos e tratamentos. Por outro lado, a maior parte das tradições religiosas possui uma relação positiva com as suas crenças religiosas e a saúde, e recomendam fazer exercícios, manter a forma física, meditar, dormir o suficiente, tomar vacinas, ter disposição para passar por um exame médico, empreender uma peregrinação por razões de saúde, dizer a verdade a respeito de como se sente, ter esperanças de recuperação, combater 0 estresse, submeter-se a exercícios físicos e aconselhamentos e ser capaz de lidar com desenvoltura com uma deficiência física (LEVIN, 2003).

Nos últimos anos, as pesquisas na ciência da saúde têm constatado que a religião é um fator psicológico e social poderoso, que influencia grandemente a saúde das 
pessoas (KOENIG, 2012). Para Koenig (idem), participar de um grupo religioso muitas vezes pode contribuir para a melhora da função imunológica, das funções endócrinas, bem como para a produção de citosinas, o combate aos distúrbios metabólicos, a luta contra a doença neurológica, cardiovascular, arterial coronariana, ou a insuficiência cardíaca congestiva, a hipertensão, o acidente vascular cerebral, a infecção, ajudando na cicatrização de feridas, no combate ao câncer e na maneira de lidar com as deficiências. Também é um fator positivo diante do índice de depressão, do controle da ansiedade, da busca pelo bem-estar, de emoções positivas, do estado de espírito elevado, do otimismo, da esperança, da longevidade, da melhoria da expectativa de vida, da qualidade de vida, dentre outros.

Portanto, de fato a religião ocupa um importante papel na saúde e, por isso, para Moreira-Almeida (2010, p. 18), "religiosidade e espiritualidade têm sido objeto de um crescente interesse entre clínicos e pesquisadores na área de saúde" — por exemplo, a epidemiologia, uma área que estuda a frequência e a distribuição de doenças na coletividade humana, ou os problemas de saúde em grupos numerosos de pessoas e, às vezes, em grupos pequenos (ROSSETTO, 2011). Considerando que as religiões se constituem grupos de pessoas com algo em comum sobre Deus, estudos feitos por epidemiológicos apontam uma relação entre a saúde e as crenças e práticas espirituais, incluindo a prece, o comparecimento a serviços religiosos, a meditação, a fé em Deus e outras. Para Levin (2003), também o vínculo social dentro de um grupo religioso influencia o comportamento humano, o qual, por sua vez, influencia a saúde.

$\mathrm{Na}$ ciência da psicologia, existem algumas abordagens sobre religiosidade/espiritualidade e saúde, dentre as quais:

a) A logoterapia - criada pelo psiquiatra vienense Viktor Frankl, trata-se de um sistema teórico-prático que procurar dar um sentido à vida e à existência do ser humano.

Em virtude da autotranscendência da existência humana, o homem é um ser em busca de sentido. Ele é dominado pela vontade de sentido. Hoje, contudo, a vontade de sentido está frustrada. Cada vez mais os pacientes voltam a nós psiquiatras queixando-se de sentimentos de falta 
de sentido e de vazio, de uma sensação de futilidade e de absurdo. São vítimas da neurose de massa hoje (FRANKL, 1989, p. 82).

A falta de sentido está também no esquecimento da autotranscendência, o que pode ocasionar neuroses e sofrimentos no paciente, cabendo aos profissionais psicoterapeutas e/ou psiquiatras ajudá-lo a encontrar sua cura por intermédio de uma harmonia entre as dimensões somática (dos fenômenos corporais e da fisiologia), psicológica (dos instintos, condicionamentos e cognições) e noética (do grego nous, que significa espírito) (CORREA, 2012).

b) A psicologia da religião - é uma parte da psicologia que busca estudar o comportamento humano e sua relação com o transcendente, as crenças, os valores, as motivações, a felicidade, a vida espiritual, a sede e a fome de Deus, o desejo e o sentido do além (FERREIRA, 2002). Sua visão é contrária à de Sigmund Freud. Em Futuro de uma llusão, Freud descreve que a religião causava sintomas neuróticos e sintomas psicóticos, não sendo, portanto, saudável. Para Barros (2000, p. 7), "a psicologia da religião pode ajudar a purificar muitas imagens ou concepções falsas ou deturpadas de Deus". Ou seja, trazer uma compreensão saudável sobre o comportamento humano com relação a Deus. Para Gomes (2009), dentro de uma visão junguiana, inúmeras neuroses estão principalmente ligadas ao fato de as necessidades religiosas da alma não serem mais levadas a sério pela psicologia.

c) A neuroteologia - também conhecida como neurociência espiritual, é uma área da saúde que busca investigar a influência da fé (crenças, religião) no cérebro humano, ou a "participação do sistema límbico nos fenômenos espirituais" (ALEJANDRO, 2015). O sistema límbico é a unidade responsável pelas emoções e pelos comportamentos, como atribuir valor sentimental às experiências emocionais: "um exemplo pode ser a sensação agradável que existe quando alguém termina uma oração ou canta para louvar" (ALEJANDRO, 2015). Para Raul Marino, médico neurocirurgião, as orações, os louvores e as meditações são pertinentes à área cerebral e podem ser um recurso para o paciente acelerar o seu processo de cura ou se adaptar ao tratamento (ALEJANDRO, 2015). 
Atualmente, existem estudos em diversas ciências da saúde, com mais constância em psicologia e neurociência espiritual, que buscam entender como as práticas religiosas e espirituais, como as orações, os louvores e as meditações, podem ser um recurso para a cura ou o enfrentamento de situações de sofrimento, estresse e problemas da vida que interferem na saúde física e mental. Este processo de recurso e enfrentamento através das práticas religiosas e espirituais se chama coping religioso/espiritual (PANZINI, 2004). O coping religioso espiritual pode ser tanto positivo quanto negativo. Como exemplos de coping religioso espiritual negativo, temos: sentir-se abandonado, descontente com Deus ou a religião, atribuir a causa do sofrimento e do problema ao pecado ou a ato demoníaco. O coping positivo relacionase a esforços em buscar sentido e propósito de vida em meio às adversidades, ainda que diante de distintas ocasiões de sofrimento, estresse etc. (PANZINI, 2004).

Para Waldir Souza (2013), em uma situação como o sofrimento, a vulnerabilidade humana se torna mais aguda, evocando significados desde força e fraqueza, medo e coragem, despertando emoções positivas e negativas na pessoa. Dentro deste contexto, a religiosidade/espiritualidade pode ajudar a responder a questões centrais sobre o sofrimento, como, por exemplo, de onde provém e para que serve ou "para onde vou depois da morte" (ZUBEN, 1993).

São estas questões que unem religiosidade/espiritualidade e a ciência da saúde, pois ambas procuram respondê-las (SOUZA, 2013). De fato, o saber médico explica o como das moléstias, já seções religiosas procuram responder o porquê (MONTERO, 1985).

Diante do acima exposto, a religiosidade/espiritualidade pode ser uma forma de contraste com a medicina e/ou ciência da saúde, a fim de reconhecer aspectos da doença e da realidade que passariam despercebidos (HAMMES, 2006). Enquanto a resposta sobre a indagação de como foi possível determinada doença se relaciona ao diagnóstico médico, a pergunta sobre o "porquê" é buscada na esfera da religiosidade/espiritualidade, como um sentido de vida diante de uma enfermidade. 


\section{A RELIGIÃO CRISTÃ E A CIÊNCIA DA SAÚDE}

A escolha pela reflexão da religião cristã está no fato de $84 \%$ dos brasileiros serem cristãos, conforme aponta o IBGE de 2010 (AZEVEDO, 2012). Outro motivo é devido à religião cristã possuir uma atuação na ciência da saúde. No início da era cristã, o cristianismo tornou-se uma religião medicinal com uma mensagem de salus para a humanidade. Na tradição patrística, em Inácio de Antioquia, encontra-se um Cristo médico "corporal e espiritual" enviado para evangelizar os pobres e curar os contritos de coração (Lucas 4:18) (ÁLVAREZ, 2013).

A ideologia do início da era cristã estende-se no decorrer da história, e até a alta ldade Média, há uma forte crença no poder milagroso do evangelho para curar as doenças (idem, p. 23). A partir do século XVI, com os avanços científicos e o lluminismo, os quais influenciaram negativamente a reflexão religiosa sobre a saúde, houve mudanças nessa perspectiva. Teólogos, como Rudolf Karl Bultmann (1884-1976), afastaram a religião da saúde. Bultmann dizia que "Já não é possível [...], em caso de doença, fazer uso da medicina moderna ou dos atuais instrumentos clínicos e, ao mesmo tempo, continuar crendo no mundo dos espíritos e dos milagres do Novo Testamento" (GESTEIRA, 1991, p. 254). Com isso, os milagres de cura começaram a suscitar inquietação, requerendo uma mentalidade científica para explicá-los.

Outro fator negativo que afastou a religiosidade da saúde está na valorização do sofrimento e da enfermidade. De acordo com Haring (1981 apud ÁLVAREZ, 2013), alguns teólogos acreditavam que Deus salvava apenas pela experiência do sofrimento e da enfermidade, pois "um corpo sadio não é com frequência um lugar habitado por Deus". Um dos motivos disto está no fato de que a ciência da religião não percebia a saúde como uma experiência humana, algo incorporado à consciência, elaborado, valorizado e estimulado, mas apenas como um estado de ausência de enfermidade ou doença (idem, p. 28).

Um progresso significativo acerca da relação entre religião e saúde se passa na década de 1960, em que o Conselho Mundial das Igrejas, uma iniciativa ecumênica, evidencia um desejo da comunidade cristã pensar na saúde dos indivíduos e da 
sociedade (idem, p. 29). Neste caso, de fato houve uma reflexão religiosa genuína sobre a saúde:

[...] especialistas europeus da pastoral no mundo da saúde se perguntavam de que modo fundamentar bíblica e teologicamente sua ação. Já não basta a teologia do sofrimento, da doença e da morte, diziase: é necessário acrescentar a "da saúde". Em diversas igrejas (e este é um dado significativo), deixara-se de falar de "pastoral do enfermos" e passara-se a falar de Pastorale de La Santé, PastoraleSanitaria, Pastoral Health Care (ÁLVAREZ, 2013, p. 30).

Outro progresso acerca da relação entre religião e saúde se deve ao teólogo Karl Barth, do século XX. Barth resgata a visão de que a saúde está ligada ao projeto de vida e de salvação do ser humano. De acordo com Roccheta (1993), para Barth, toda concepção de salvação no Antigo e no Novo Testamento relaciona-se com a saúde, desde a criação, o alimento, o trabalho, o descanso, a doença, a morte e a promessa de salvação esperada por Israel e realizada em Cristo.

$\mathrm{Na}$ contemporaneidade surgiram importantes reflexões religiosas cristãs sobre a saúde. Existem diversas disciplinas e ênfases teológicas inseridas na saúde:

a) A teobiologia. É a relação entre a teologia e a biologia. Visto que os seres humanos são organismos incorporados, os instrumentos da psicologia, da biologia e da psicofisiologia podem ser utilizados para elucidar as relações entre teologia, corpo humano e experiência religiosa (PANZINI, 2004).

b) A teologia do corpo. Ganha expressividade no pontificado do papa João Paulo II, como título de trabalho para suas primeiras catequeses, ministradas entre 1979 e 1984 durante as Audiências Gerais. Nelas, o papa abordou assuntos referentes à vida cristã, entre eles a saúde, a relação do homem e da mulher no significado esponsal do corpo humano, a natureza e a missão da família, o matrimônio, o celibato, a luta espiritual do coração do homem e a linguagem profética do corpo humano.

c) Dentro da reflexão teológica sobre a mensagem cristã em ação e a missão da Igreja na sociedade, surge a teologia prática, que busca praticar os ensinamentos teológicos através de ações pastorais destinadas as pessoas em diferentes situações, como: 
imigrantes, carcerários, crianças, juventude, idosos e enfermos. Nesta última, situase a ação da pastoral da saúde. Conforme o Documento de Aparecida, a Pastoral da Saúde busca dar "resposta às grandes interrogações da vida, tais como o sofrimento e a morte, à luz da morte e da ressurreição do Senhor". Sua finalidade é "promover, cuidar, defender e celebrar a vida, tornando presente na história o dom libertador e salvífico de Jesus, que veio trazer-nos vida e vida em abundância" (DURÃES E SOUZA, 2011, p. 11). Dentro do contexto teológico da saúde, a abundância é ter sentido de viver mesmo em meio à condição humana da enfermidade. Isto se torna um ato libertador na medida em que não se limita a saúde apenas em ter (ou não) uma enfermidade. Portanto, a vida em abundância em Jesus é uma vida que transcende a condição humana da enfermidade, ou seja, não é trazer apenas uma vida com saúde, mas vida de salvação. Para Martins (2010), a Pastoral da Saúde é a relação entre a comunidade cristã e os diversos ambientes ligados à saúde, desde instâncias políticas, como os conselhos locais de saúde, até visitas solidárias aos enfermos em hospitais e domicílios.

d) Na década de 1960 surge uma teologia relacionada à missão da Igreja na libertação das opressões sociais, políticas, econômicas que sofre o povo latino-americano. A teologia da libertação impulsiona comunidades compostas por membros insatisfeitos das classes populares a lutarem por moradia, transporte, saneamento básico, iluminação pública, educação, creche e saúde (ROSSI, 2002).

e) A teologia moral. Trata de questões que envolvem a moral humana e, especificamente, procura orientar os cristãos diante da realidade da vida, incluído vários temas sobre a saúde - como, por exemplo: a cibernética, a clonagem, a dignidade humana, embrião e feto, as pesquisas com células-tronco embrionárias, a tecnologia médica, a nanotecnologia, o envelhecimento e o idoso, as intervenções antienvelhecimento, os pacientes terminais e as grandes questões éticas (TRASFERETTI, 2013).

f) Destaca-se, ainda, a proposta do teólogo Camiliano Francisco Álvarez sobre uma teologia da saúde. Para Álvarez (2013), uma teologia da saúde se fundamenta em um discurso teológico orientado para a práxis cristã e pastoral, em que a saúde é um dom 
e uma missão da igreja, manifesta na vivência individual e comunitária da fé com a proclamação da história salvífica de Deus, e uma harmonia dinâmica entre corpo, psique e o espírito. Por isso, a ciência da religião como, a teologia da saúde precisa buscar contraste com a psicologia e a medicina com objetivo de harmonizar o anúncio da salvação e os serviços em saúde, como a prática do cuidado hospitalar.

\section{A TRADIÇÃO CRISTÃ E OS PROFISSIONAIS DA SAÚDE}

Durante a história da humanidade, o trabalho com saúde sempre esteve ligado à religiosidade/espiritualidade.

Seria uma impropriedade teórica iniciar a caracterização da Medicina sem ligá-la à Religião, visto que um dos aspectos mais evidentes no advento da Medicina é a íntima associação da mesma com a magia e a religiosidade, sendo esta uma constante em todas as civilizações e épocas (HEIMANN, 2003, p. 67).

De fato, medicina e religião são áreas que têm em comum a questão do cuidado humano, expresso na atenção à saúde. A medicina contemporânea foca-se, sobretudo, no cuidado com a saúde física, enquanto a religião olha a saúde desde uma perspectiva espiritual, com ênfase na relacionalidade (cuidado na relação com outros, consigo próprio e com a transcendência). Muitas civilizações antigas desenvolveram seu serviço de saúde na figura de um sacerdote médico, como, por exemplo, o poder divino de cura nas figuras dos xamãs, dos pajés das tribos indígenas, dos druidas das antigas civilizações europeias e dos curandeiros e feiticeiros das tribos africanas e da Oceania (BOTSARIS, 2011).

Dentro da tradição cristã há evidências da relação entre os clérigos/religiosos e o serviço da saúde. Encontra-se, por exemplo, dentre os apóstolos de Jesus, São Lucas, um médico evangelista. Conforme a apresentação histórica de Alexsandro Silva (2010), para Justino (ca. 100-165), prestar serviços aos enfermos era uma condição indispensável para ser um diácono ou participar da comunidade cristã. $\mathrm{O}$ teólogo Éfrem (ca. 306-373) construiu um hospital em Edessa para infectados pela peste. Os bispos Eustácio de Sebaste (ca. 356-380), Basílio (ca. 360-379) e João Crisóstomo (ca. 347-407) construíram hospitais para os leprosos. São Cesário de 
Arles (ca. 470—543) fundou um hospital junto à sua catedral. São Bento (ca. 480— 547) praticava a hospedaria e a enfermaria nos mosteiros e nos jardins botânicos desenvolvia a farmacopeia[2]. Cassiodoro (ca. 490-581) foi uns dos primeiros monges médicos. São Roque (ca. 1295-1317), considerado padroeiro de diversas profissões ligadas à saúde, estudou medicina e desejou a vida religiosa na causa dos enfermos. Frei João Gilbert Joffré em 1409 criou uma das primeiras instituições psiquiátricas com terapia ocupacional, ou seja, sem o tratamento de tortura. São João de Deus (ca. 1495-1550) e São Camilo de Lellis (ca. 1550-1614), devido às suas dedicações aos serviços de saúde, foram declarados por Leão XIII (1886) padroeiros dos doentes, dos hospitais e dos profissionais da saúde. São Luís Gonzaga (ca. 1568-1591) faleceu em Roma cuidando dos enfermos. O cardeal São Carlos Borromeu (ca. 1538-1584) se envolveu tanto na causa dos enfermos que chegou a ter uma moradia no hospital. São Martinho de Porres (ca. 1679-1639) deu assistência aos enfermos de todas as etnias. São Vicente de Paula (ca. 1581-1660) foi um grande militante social das causas estruturais da pobreza e da doença. Santa Luisa de Marillac (ca. 1591-1660) fundou com São Vicente a congregação das "Filhas da Caridade", que criou hospitais e casas de assistência aos doentes (SILVA, 2010, pp. 17-22).

Lentamente, na baixa Idade Média e no início da modernidade, diminui-se o papel do clérigo médico devido aos avanços dos cursos de medicina nas universidades de Bolonha, Paris, Oxford e Salamanca, que passam a conferir à categoria médica um título de doutor no intento de caracterizar e oficializar uma identidade ocupacional, pois antes disto os médicos eram vistos como curandeiros, figura que, por vezes, estava ligada ao sacerdócio (LANDMANN, 1984). A própria Igreja também notou esta necessidade de uma identidade ocupacional para o médico, pois muitos clérigos perderam a sua vocação religiosa por terem mais atribuições médicas do que eclesiásticas. Neste sentido, o Concílio de Clermont, no século 11, reprovou a participação dos clérigos em operações médicas (XAVIER FILHO, 1993). O papa Inocêncio III (1139) também proibiu o clérigo no exercício da medicina. Bonifácio VIII (1302) corroborou esta proibição (ALARCOS, 2006). 
Todavia, segundo Pitta (1991), somente a partir do século 19 os médicos passam a cumprir seu ofício e sua ocupação sem atrelamento a um aspecto religioso/espiritual, devido ao foco tecnológico e à prestação de serviços advinda da Revolução Industrial, em que o modelo médico-sacerdote passou a ser visto como algo artesanal. Surge, então, um modelo técnico de trabalho de saúde, e os profissionais da saúde assumem funções específicas, "como por exemplo o médico clínico, o laboratorista, a enfermeira, a fisioterapeuta, a cirurgiã, os atendentes, etc." (HEIMANN, 2003, p. 37).

$\mathrm{Na}$ contemporaneidade, este modelo pautado pela eficiência técnica e pelo foco na prestação dos serviços é prevalecente, tendo isto um lado positivo quando a tecnologia ajuda a curar e a tratar doenças que em séculos passados eram incuráveis, proporcionando melhor qualidade de saúde à humanidade. Contudo, o uso indiscriminado da tecnologia, ainda que apinhado de boas intenções, pode resultar no abandono, muitas vezes não intencional, de outras dimensões humanas respeitáveis, como o conforto e o controle da dor, a comunicação, os valores significativos e, especialmente, as questões espirituais e religiosas. Neste sentido, surge "um desafio aos profissionais da saúde para responder às questões sobre o equilíbrio entre saúde e espiritualidade" (PERES, 2007, p. 86). Ou seja, uma retomada em integrar a religiosidade/espiritualidade como parte do trabalho dos profissionais da saúde.

\section{CONSIDERAÇÕES FINAIS}

1- Considera-se que as noções etimológicas da espiritualidade e a saúde estão associadas nos significados, tais como, no sentido e propósito de vida, isto influencia a ciência da saúde e da religião, tanto no significado acadêmico dos termos como nas práticas do cuidado entre os profissionais da saúde, que atualmente buscam uma visão integral entre o corpo e o espírito.

2- Considera-se que existem grupos religiosos que se propõem a buscar a saúde como uma de suas finalidades religiosas. São religiões que prescrevem e proscrevem doutrinas ou ensinamentos sobre um comportamento saudável. Neste contexto, devido à maior parte da população ser cristã, utilizou como exemplo a religião cristã. Neste sentido, aponta-se que todas as religiões associam a prática espiritual com o 
estado de saúde-doença (LEVIN, 2003). Assim sendo, necessários novos estudos sobre outras tradições religiosas e suas óticas sobre a saúde. Tais como, o espiritismo, que entende a noção de saúde como o funcionamento, a interação, com estabilidade, a qual todo ser humano (encarnado) é composto Espírito-PeríspiritoMatéria. Também, são necessários estudos sobre os grupos sem religião, que podem entender a noção de saúde como algo relacionado ao estado de espírito, a alegria e a triste, o bom e o mau, ao invés das práticas religiosas (GERONE, 2015).

3- Considera-se que pesquisas da área da saúde constatam que a religião é um fator psicológico e social poderoso, que influencia grandemente a saúde das pessoas, as práticas e o comportamento saudável, a alimentação, a medicação e outros. Neste sentido, a ciência da saúde, tais como, neurologia, neurociência e a psicologia podem pesquisar sobre o efeito psicosocioneurológico da Fé no processo de doença-saúde, tais como, o impacto do coping religioso-espiritual na recuperação e no tratamento médico.

4- Considera-se que atualmente existem áreas da saúde inseridas na ciência da religião, tais como, a psicologia da religião. Existem áreas da religião inseridas na saúde, tais como, as reflexões teologias. Neste sentido, são necessários novos estudos em ambas as ciências, que possuam uma visão interdisciplinar sobre a espiritualidade e a saúde.

5- Considera-se que a religião está associada historicamente com a saúde, especialmente neste estudo, percebe que a religião cristã desenvolveu ao longo do tempo serviços de saúde. Sendo comum encontrar sacerdotes médicos, ou, práticas religiosas no cuidado em saúde. Este processo histórico juntamente com a maior parte de a população ser cristão desafia os profissionais da saúde em lidar com as questões sobre a saúde e a espiritualidade.

\section{REFERÊNCIAS}

ALARCOS, Francisco J. Bioética e pastoral da saúde. São Paulo: Paulinas, 2006. 
ÁLVAREZ, F. Teologia da saúde. São Paulo: Paulinas/Centro Universitário São Camilo, 2013.

ALEJANDRO, I. "Neuroteologia e as bases das crenças". Disponível em: http://www.institutodehipnose.com/search/label/NEUROTEOLOGIA\%20AS\%20BAS ES\%20DA\%20CREN\%C3\%87A. Acesso em 22 de maio de 2015.

AZEVEDO, R. "O IBGE e a religião - Cristãos são $86,8 \%$ do Brasil; católicos caem para 64,6\%; evangélicos já são 22,2\%”. Disponível em: <http://veja.abril.com.br/blog/reinaldo/geral/o-ibge-e-a-religiao-\%E2\%80\%93cristaos-sao-868-do-brasil-catolicos-caem-para-646-evangelicos-ja-sao-222/>. Acesso em 29 de julho de 2014.

BARROS, J. "Felicidade: teorias e factores". Psicologia, Educação, Cultura, 4 (2), 281-309.

BíBLIA DE JERUSALÉM. São Paulo: Paulus, 2002.

BíBLIA SAGRADA. Edição Revista e Corrigida. São Paulo: Sociedade Bíblica do Brasil, 1969.

BOTSARIS. A. S. Sem anestesia: o desabafo de um médico. Os bastidores de uma medicina cada vez mais distante e cruel. Rio de Janeiro: Objetiva, 2001.

CORREA, W. H.; HOLANDA, A. F. Prostituição e sentido de vida: relações de significado Psico-USF. Disponível em:

$<$ http://www.scielo.br/scielo.php?script=sci_arttext\&pid=S1413-

$82712012000300009 \& \operatorname{lng}=e n \& n r m=i s o>$. Acesso em 14 de junho de 2014.

DERRIDA, Jacques; VATTIMO, Gianni (orgs.). A religião: o seminário de Capri. São Paulo: Estação Liberdade, 2000.

DURÃES, J.; SOUZA, W. "A pastoral da saúde e o SUS: para que todos tenham vida em abundância". In: Anais do II Congresso de Humanização I Jornada Interdisciplinar de Humanização, 2011. 
FERREIRA, J. Psicologia, educação e cultura v. I. Colégio Internato dos Carvalhos, 2002.

FRANKL, V. E. Um sentido para vida. Aparecida: Santuário, 1989.

GERONE, Lucas Guilherme Teztlaff de. Um olhar sobre a Religiosidade/Espiritualidade na Prática do Cuidado entre profissionais de saúde e pastoralistas. Dissertação (Mestrado em Teologia) - Escola de Educação e Humanidades. Pontifícia Universidade Católica do Paraná. Curitiba, 2015. Disponível em: <http://www.biblioteca.pucpr.br/tede/tde_busca/arquivo.php?codArquivo=3116>. [Acesso em 27 dez. 2019.]

GESTEIRA, M. "Christusmedicus. Jesús ante el problema del mal”. Revista Española de Teología, Madri: Cristiandad, 1991.

GOMES, V; FERRET, J. "A religião na obra de Jung: contribuições para a compreensão do homem moderno". In: Anais do Encontro Internacional de Produção Científica. Maringá: Cesumar, 2009.

HAMMES, J. "Pode teologia ser ciência?" Rev. Trim. Porto Alegre, Porto Alegre, v. 36 , n. p. 153 , setembro de 2006.

HEIMANN, T. Cuidando de cuidadores: acompanhamento a profissionais que assistem pacientes em UTI'S - uma abordagem a partir da psicologia pastoral. Dissertação de Mestrado em Teologia. São Leopoldo: Escola Superior de Teologia, 2003.

KOENIG, H. Medicina, religião e saúde: o encontro da ciência e da espiritualidade. Porto Alegre: LMP, 2012.

LANDMANN, Jayme. A outra face da medicina: um estudo das ideologias médicas. Rio de Janeiro: Salamandra, 1984.

LEVIN, J. Deus, fé e saúde - explorando a conexão espiritualidade-cura. São Paulo: Cultrix, 2003. 
LUZ, M. Origem etimológica do termo. Diponivel em: <http://www.epsjv.fiocruz.br/dicionario/verbetes/sau.html>. Acesso em $1^{\circ}$ de outubro de 2013.

MARTINS, A. "A Pastoral da Saúde e a sua importância no mundo da saúde: da presença solidária ao transcender a dor e o sofrimento". O Mundo da Saúde v. 34, n. 4, São Paulo, pp. 547-552, out/dez. 2010.

MONTERO, Paula. Da doença à desordem: a magia na Umbanda. Rio de Janeiro: Edições Graal, 1985.

MOREIRA-ALMEIDA A, et al. "Envolvimento religioso e fatores sociodemográficos: resultados de um levantamento nacional no Brasil”. Revista de Psiquiatria Clínica v. 37, n. 1, 2010. Disponível em: <http://www.scielo.br/scielo.php?pid=S010160832010000100003\&script=sci_arttext>. Acesso em 29 de setembro de 2013.

MOREIRA-ALMEIDA, A. Metodologia de pesquisa para estudos em espiritualidade e saúde. Arte de cuidar: saúde, espiritualidade e educação. Bragança Paulista: Comenius, 2010.

"O que é teologia do corpo?" Disponível em: <http://teologiadocorpo.com.br/o-que-ea-teologia-do-corpo/>. Acesso em 2 de abril de 2014.

PANZINI, R; ROCHA, N; BANDEIRA, D; et. al. "Qualidade de vida e espiritualidade". Rev. Psiq. Clín. v. 34, pp. 105-115, 2007.

PANZINI, R. Escala de coping religioso-espiritual (escala cre). Dissertação de Mestrado em Psicologia. Porto Alegre: Universidade Federal do Rio Grande do Sul, 2004

PERES, M. F. P. et al. "A importância da integração da espiritualidade e da religiosidade no manejo da dor e dos cuidados paliativos". Revista Psiquiatra Clínica, São Paulo, $\quad$ v. $\quad 34, \quad 2007 . \quad$ Disponível em 
<http://www.scielo.br/scielo.php?script=sci_arttext\&pid=S010160832007000700011\&lng=pt\&nrm=iso>. Acesso em 16 de dezembro de 2013.

PITTA, A. Hospital: dor e morte como ofício. São Paulo: Hucitec, 1991.

PUCHALSKI, C. M. "Espiritualidade e medicina: os currículos na educação médica". Journal of Education Câncer: O Jornal Oficial da Associação Americana para a Educação do Câncer, 21 (1), pp. 14-18, 2006.

ROCCHETTA, C. "Salute e salvezzaneigestisacramentali". Camillianum v. 7, pp. 927, 1993.

ROSSETTO, E. Epidemiologia e vigilâncias em saúde. Brasília: W Educacional, 2011.

ROSSI, W. "A Teologia da Libertação e as transformações do mundo". Revista Espaço Acadêmico n. 17, out. 2002.

SILVA, A. A capelania hospitalar: uma contribuição na recuperação do enfermo oncológico. Dissertação de Mestrado em Teologia. São Leopoldo: Escola Superior de Teologia, 2010.

SOUZA, W. "A espiritualidade como fonte sistêmica na Bioética". Rev. PistisPrax., Teol. Pastor., Curitiba, v. 5, n. 1, pp. 91-121, jan./jun. 2013.

TRASFERETTI, J. "Teologia moral, bioética e cultura da morte: desafios para a Pastoral". Rev. PistisPrax., Teol. Pastor., Curitiba, v. 5, n. 1, pp. 147-168, jan./jun. 2013.

WHOQOL Group. "The development of the World Health Organization quality of life assessment instrument”. In: J. ORLEY; W. KUYKEN (eds.). Quality of life assessment: International perspectives. Heidelberg: Springer Verlag, 1994.

XAVIER FILHO, E. O homem e a cura. Porto Alegre: Rígel, 1993. 
ZUBEN, N. "A filosofia e a condição humana". Faculdade de Educação, UNICAMP, Vol. 4, n. 3, nov. 1993. Disponível em: <http://www.fae.unicamp.br/vonzuben/filos.html>. Acesso em 11 de abril de 2014.

\section{APÊNDICE - REFERÊNCIA DE NOTA DE RODAPÉ}

2. Arte e técnica de preparar medicamentos básicos, princípios ativos e coadjuvantes, insumos e compostos.

Enviado: Agosto, 2020.

Aprovado: Setembro, 2020. 